\title{
Assessing the economic impacts of crises: a decision-support approach to long-term strategic planning
}

\author{
M. Räikkönen ${ }^{1}$, K. Pilli-Sihvola ${ }^{2}$, S. Kunttu ${ }^{1}$, J. Yliaho ${ }^{1}$, M. Jähi ${ }^{1}$ \\ G. Zuccaro ${ }^{3} \&$ D. Del Cogliano ${ }^{4}$ \\ ${ }^{1}$ VTT Technical Research Centre of Finland, Finland \\ ${ }^{2}$ Finnish Meteorological Institute, Finland \\ ${ }^{3}$ Università di Napoli Federico II, PLINIVS-LUPT Study Center, Italy \\ ${ }^{4}$ Eureka Comunicazione Telematica, Rome, Italy
}

\begin{abstract}
The assessment of economic impacts of crises and risk reduction generated by different mitigation measures is a multidimensional problem and often a challenging task. A major issue hindering the process is a lack of structured information. In particular, intangible losses are difficult to evaluate monetarily. Furthermore, the uncertainty related to the operational environment is difficult to estimate. This paper proposes a practical economic approach that aims at assessing different measures to mitigate the impacts of the crises. The purpose is to contribute to the understanding of the decision-making related to crisis management so that the goals of the decisions can be reached. The approach is mainly aimed at enhancing decision-making on a strategic level and at supporting crisis-management training. Additionally, a software tool based on the approach will be developed to make the assessment procedure usable in practice. The approach is demonstrated in two pilot cases: extreme winter storm in North of Finland and a major earthquake in Italy. The paper is based on research carried out in the CRISMA integration project which is funded by the European Community's Seventh Framework Programme.

Keywords: cost, benefit, crisis, decision-making, mitigation measure, economic impact.
\end{abstract}




\section{Introduction}

Nowadays, the risks of crises are surrounding us practically everywhere. Although partial risk reduction (or mitigation) is feasible by introducing and implementing different measures to mitigate the impacts of the crises, they continue to occur and can cause severe damage to physical assets and lives and livelihoods [1]. Hence, decision-makers at all decision-making levels are pressured to find ways to cope with the impending crises, increase awareness of the overall impacts and to have a thorough understanding of the economic impacts of the crises. It is evident that decision-makers usually find themselves confronted with the situation where they have to balance the uncertainties in potential impacts, economic costs, time, resources, the level of information and other possible priorities [2]. In this respect, estimates of and other information on the costs and benefits of the mitigation measures and crisis impacts are crucial for decision-making and for the development of strategies and measures to prevent or reduce the impacts.

To support reliable, cost-effective, efficient, and transparent decision-making on the mitigation measures, different investment appraisal and cost assessment methods can be applied. A considerable amount of research is done in this area and the general features of these methods are well known [3-6]. Additionally, a variety of methodological approaches on the economic assessment of alternative risk mitigation measures exists. These are based, for example, on cost-benefit analysis (CBA) and life cycle costing approaches (LCC) [3, 7-9].

It is generally accepted that the assessment of the mitigation measures should cover both the investment and operating costs and the benefits (i.e. the avoidance or reduction of negative consequences of the crises) of a measure or a set of measures. Mitigation investments include, for example, physical assets, engineering techniques and hazard-resistant constructions, and improved policies, plans and actions taken to avoid, reduce the severity of, or eliminate the adverse impacts of crises. Furthermore, costs of rescue and emergency services in the response phase should be included [3]. Often the assessment is a challenging task, as the methodology to assess economic losses is not standardized $[10,11]$.

The costs and benefits of the mitigation measures can be further divided into direct and indirect as well as tangible and intangible. However, often the assessment of risk mitigation measures focuses almost exclusively on the direct costs, rather than indirect or intangible costs. The main reason is that the direct costs are most straightforwardly expressed in monetary terms $[3,10$, $12-14]$. It is also relatively simple to find data on direct costs. This indicates that the assessments are often under pressure to demonstrate short-term effects $[3,10$, 12-14]. Additionally, the assessments tend to concentrate only on direct investments on "hard" mitigation measures, such as infrastructure investments, rather than on non-structural measures, such as small-scale mitigation actions, monitoring and warning systems and emergency response capacities [3].

An economic assessment usually entails considerable uncertainties. For example, data sources can be insufficient or highly aggregated [3] and 
uncertainties related to the operational environment create confusion. Uncertainties can enter the assessment at different points (e.g. data uncertainty, parameter uncertainty and model uncertainty) which all affect the decisionmakers' perception of the usefulness of the results [2]. However, only a few practical analyses to integrate uncertainty aspects systematically into the decision-making exist, and as a result, almost no practical solutions appear to be available. Furthermore, we argue that many analytical and normative models to aid decision-making on mitigation measures are often too theoretic and complicated to be used in a practical context (see e.g. $[3,10,13,14-16])$.

\section{Objectives and method}

The aim of this paper is to contribute to the practical assessment on the economics - costs and benefits - of mitigation measures (and assets more broadly) for crisis management in a way that the goals of the decisions can be reached. This paper is based on research carried out in the CRISMA integration project, funded from the European Community's Seventh Framework Programme. CRISMA is aiming to support both public and private crisis managers and decision-makers in short- and long-term planning, and training and reviewing of crisis preparedness and response organisations, infrastructure and personnel [1]. As a main outcome, CRISMA will develop a simulation-based decision support system. One component of the CRISMA decision support system is a software tool based on the economic evaluation approach presented in this paper.

The underlying research question of this paper is: how to assess in a practical way the investments aiming at reducing the negative impacts of crises? The two more specific objectives of the paper are:

- To propose a practical framework for the economic assessment of mitigation measures that will serve especially the strategic decisionmaking.

- $\quad$ To examine how to manage uncertainty in the assessment of mitigation measures.

The main research methodology is constructive research. A content analysis was used to examine and compare the past and present methods of investment appraisal, CBA and LCC analyses and to discuss the different aspects of decision-making and uncertainty management in this context. The actual approach and software prototype development is based on problem solving and solution building. The approach is demonstrated in two pilot cases: extreme winter storm in North of Finland and major earthquake in Italy.

\section{Approach}

\subsection{Assessment of costs and benefits of different mitigation measures}

The primary purpose behind the assessment of the costs and benefits of different mitigation measures is to determine the long-term implications of decisions. An 
important aspect is to assess an optimal level for the risk mitigation investment [17]. The assessment procedure for risk mitigation investments can be more or less analytical in depth, depending on the context and the actual case within that context (e.g. coastal submersion, earthquake, extreme winter storm, chemical spill and a large traffic accident in CRISMA). The level and type (qualitative, quantitative, or semi-quantitative) of detail in the assessment should be consistent with the level of the decision (e.g. local, national, or EU) [2].

\subsection{Proposed assessment procedure}

The approach proposed in this paper is based on the assessment of avoided or reduced negative consequences (benefits) generated by different mitigation measures. It can be considered as a decision-support approach to be applied in the investment planning phase. The main target group of the approach is authorities on different levels of public decision-making. In addition, the economic assessment can produce information for other purposes, for instance for insurance companies, private sector investors or international aid providers. The approach supports the decision-makers as it creates a common understanding of the decision alternatives and their possible consequences before the decision takes place. To meet the expert competence requirements, the analysis should be carried out in an expert session. One key for making successful decisions is the ability of the decision-maker to recognise and use external and internal sources of economic and damage information (e.g. databases, statistics, expert judgement) and to read weak signals. Furthermore, the decision-maker needs to efficiently take advantage of existing information and knowledge.

The proposed approach follows the passage from vulnerability analysis and potential damage estimation to loss assessment, focusing on answering the question of how such "damage" may be converted into economic losses. The basis for the assessment is a baseline scenario which presents the impacts of the crises without any implemented mitigation measures. This baseline scenario is then compared with a scenario including some mitigation measures(s) to evaluate the benefits, i.e. change (reduction) in damage and cost. The procedure (see Fig. 1) can be applied to determine the economic effectiveness of different mitigation investments and to compare them with each other.

The approach aspires to systematically consider all present and future costs and benefits of mitigation investments. The 'benefit' part usually includes intangible benefits (e.g. lives saved, personal memorabilia not destroyed), which are difficult to measure solely in economic terms. However, the assessment should include each cost and benefit that is appropriate with each specific measure, tailored to fit the situation. The assessment approach comprises of seven general, pre-defined cost and benefit types: investment and operating costs of mitigation measures, rescue and emergency costs in the response phase, costs/benefits of the impacts on human health, property, lifelines, nature and agriculture. 


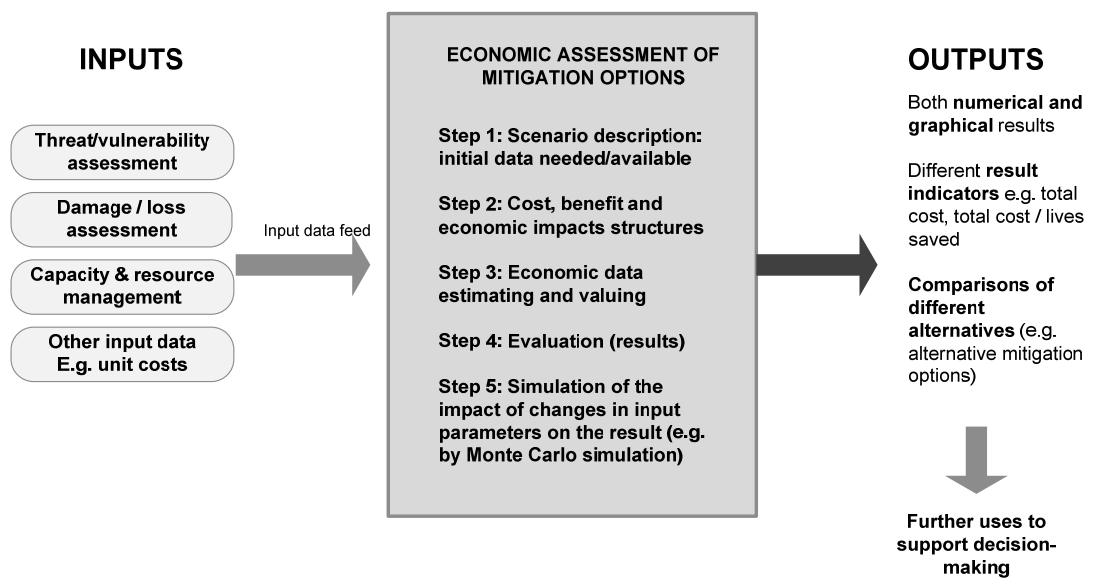

Figure 1: The process for the economic assessment of mitigation options.

There are a number of alternative methods for valuing the impacts of crises (e.g. shadow prices, replacement cost method, production method, substitute or proxy method, change in earnings, hedonic pricing, travel cost method, willingness to pay) which are suitable for different purposes, and vary in how accurately they present the value of damages. The chosen method should always reflect the decision situation at hand, the possibility to assign monetary values for different costs and benefits and data availability.

\subsection{Results of the proposed approach}

As a result of the assessment, different types of result indicators, e.g. cost summaries as well as graphs, can be illustrated. Effectiveness and efficiency are key outcomes in determining the best option from a set of measures. Typically, cost-effectiveness relates the cost of a mitigation measure to its key outcomes or benefits (see for example [18]). The number of lives saved is an obvious unit of effectiveness. Opportunity to compare the benefits of different physical investments, plans and actions enhances the transparency of decision-making and also supports the long-term planning and decision-making. An example of a result graph is presented in Fig. 2.

In all, the economic assessment of the mitigation measures has to be flexible to handle different crises with distinct cost factors. The level of available data varies case by case and the assessments have to allow calculations based on detailed data as well as rough calculations with imprecise data.

\section{Reliability of the results}

The key issue in considering the usefulness of the results of the economic assessment for decision-making is the reliability of the assessment, which in this case is mainly dependent on the completeness of cost and benefit structures and the availability of monetary values for parameters. 


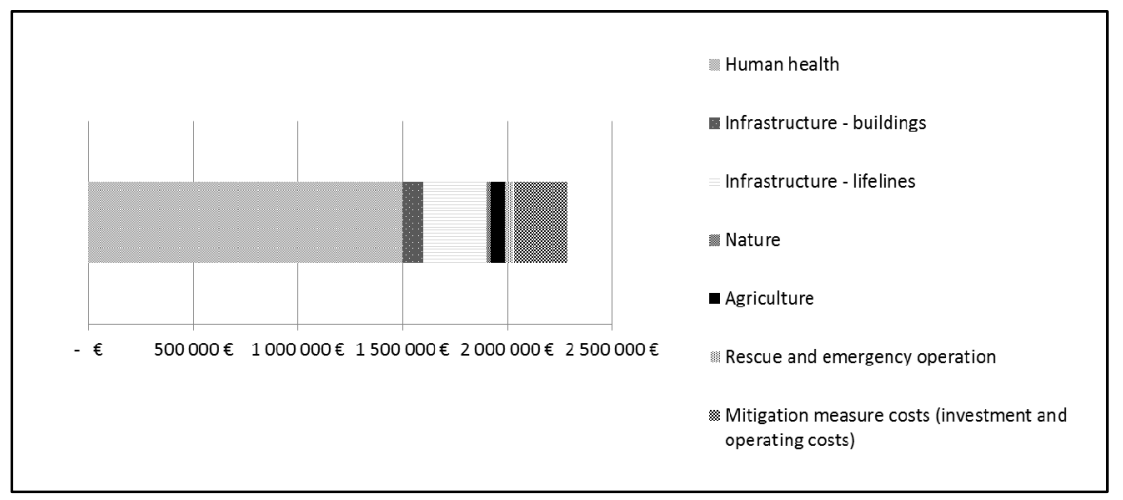

Figure 2: Example of a result graph generated by the tool based on the developed approach.

The cost and benefit structures are always case specific and need to be defined by a user of the final software tool. Thus, inclusion of all relevant cost and benefit categories and parameters is dependent on the user's expertise. To assist the user in the cost and benefit structure definition, a pre-defined structure is given as a starting point. However, the default structure might require substantial modification before the cost and benefit parameters are appropriate for the case.

The economic assessment requires a considerable amount of data which cannot be verified because it does not necessarily exist at the time decisions are made. Thus, the best available estimates of monetary values need to be defined. For example, if market values for costs and benefits are available, they can be used. If not, different valuation methods, mentioned in Section 3.2, can be applied. However, there always needs to be a balance between time, resources, and the level of information: typically, decisions have to be made with less than perfect data and in a given timeframe. One method to assess the effect of uncertain monetary values on result indicator values is sensitivity analysis, presented briefly in the next section.

\subsection{Sensitivity analysis}

The economic assessment of mitigation measures is mostly based on the estimates of inherently uncertain future values of the economic parameters. The robustness of the assessment for the change in the parameters can be evaluated by a sensitivity analysis. The simplest way to conduct a sensitivity analysis is to change an initial value of the cost or benefit parameter and recalculate the result indicator values, i.e. to conduct a what-if analysis.

In the proposed approach, the sensitivity analysis is performed with Monte Carlo simulation using statistical triangular distribution. Triangular distribution is defined by three values: expected minimum, maximum and mode, which is the most probable value. This distribution is selected because it is simple to understand and to define by an average user with limited knowledge about 
statistical distributions, and because in practice much more than minimum, maximum and mode estimates are not available for the distribution definition.

The sensitivity analysis can be performed for one or several different cost and benefit parameters at a time, and the result is the variation in the result indicator values. By selecting only one or few cost and benefit parameter values to be simulated, it is possible to study the effect of certain parameters on the result indicator values.

\section{Case studies}

\subsection{Case study I}

The first case study describes a crisis situation due to extreme winter conditions and a heavy winter storm in North of Finland, leading to substantial damage to the electricity distribution network due to the snow load and broken trees. After the storm has passed the area, a prolonged cold-spell arrives. Due to the difficult conditions, snow clearing and repairing the damaged networks are put under heavy pressure. This combined with long power outages causes a need for evacuation of the vulnerable population.

\section{Mitigation measure investments (investment costs, operating costs)}

The most relevant measure to reduce the impacts of the crisis is the training of the emergency and rescue personnel and improved preparedness of the stakeholders involved, as they have the potential to decrease the adverse impacts substantially. These with the potential impacts will be applied in the final tool to assess their cost-effectiveness. Moreover, an important mitigation measure in extreme weather events is a multi-hazard early warning system which will also be evaluated from a financial perceptive.

Regulations on fire places and generators would pose a cost burden on the households and institutions, such as elderly people's homes and hotels, accommodating vulnerable population. The benefits of the regulation will be evaluated with the tool.

The most significant mitigation measure would be major investments in the electricity network and housing - ground electricity cables, fire places and generators - to reduce the vulnerability of the electricity distribution network and the affected people and property. The investment cost of the ground cables is high and falls to private electricity distribution companies, but they have the potential to reduce the impacts of the event practically to zero, as snow and fallen trees cannot damage the distribution network. However, as the main users of the tool will be officials, this measure will not be evaluated.

\section{Rescue and emergency costs}

The costs of rescue and emergency operations are the main focus of Case Study

I. The main cost category in the rescue and emergency costs is the compensation for the overtime hours for each member of the permanent staff. Furthermore, the 
cost of the working hours of any back-up staff is calculated. The cost of use of helicopters and snowmobiles is calculated. Daily cost consists of number of rescue units $\mathrm{x}$ the cost of unit $\mathrm{x}$ the use of unit (hour or $\mathrm{km}$ ). The total rescue and emergency costs are the daily cost times the number of days the event lasts.

\section{Direct damage costs}

The main focus of the direct impact calculation is on the impacts on human health: injured and evacuated people, and possible fatalities, and the impacts on the maintenance of the electricity and road networks. For road network, the costs occur due to the increased number of accidents and clearing the roads from snow. Quick repairing of the electricity network is crucial for the impact mitigation and to avoid evacuations. In challenging conditions, this requires increased number of workforce and equipment. The cost and benefit of overtime and back-up staff will be evaluated with the tool. An important cost category is the compensation for cross-border help, in case additional helicopters are needed or patients have to be sent to hospitals outside of Finland.

\section{Indirect damage costs}

The most severe indirect, tangible cost category is the increase in the price of electricity network maintenance and damage repair of houses, if there is demand surge in the area and workforce arrives from other areas in Finland or from neighbouring countries. Indirect, intangible damage in the winter storm event occurs if there are long-term impacts on human health.

\subsection{Case study II}

The second case study describes a crisis situation due to an earthquake in Italy (Central Eastern Area), followed by a fire, caused by a cascading effect of the earthquake (an electrical short circuit generates a fire that spreads over a wide area of the area struck by earthquake).

\section{Mitigation measure investments (investment costs, operating costs)}

The most important measure to reduce the costs resulting from the effects of the earthquake is a decrease in vulnerability of buildings with interventions to improve their seismic performance (move the vulnerability class), at least for the building located close to the Life-lines.

The cost of "Mitigation Policies" is related to the activities provided for the risk reduction. The risk can be mitigated by working on the consistency of the value exposed to the hazard and on its vulnerability for the different kinds of buildings.

Since the mitigation activities are focused on vulnerability reduction, for the buildings on which mitigation is done there is an inverse relation between mitigation costs and building reconstruction/rehabilitation costs [19].

This category included the costs related to the activities provided for the communication of the emergency plan and for the information/dissemination. For the Fire hazard the mitigation activities are mainly represented by fire spreading barriers. 
This category also includes the costs related to the activities provided for the communication of the emergency plan and for the information dissemination.

\section{Rescue and emergency costs}

The main costs under rescue and emergency category are [19]:

- Evacuation direct costs: related to the activities provided for the evacuation of the population from the affected area, according to the specific needs included in the individual municipal plans.

- Evacuation assistance costs: related to the activities provided for giving continuous assistance to the population evacuated from the emergency area.

- Emergency costs: related to the activities and to the units engaged in the emergency phase as operating structures, vehicles, equipment, and volunteers. For example, the cost related to the number of people committed in each operating structure to manage the emergency (Civil Protection Department personnel, police, forest corps, etc.) and the organization of equipped area are included in this group.

\section{Direct damage costs}

The main direct damage costs in Case II are the following [19]:

- Rubble cleaning-up costs: related to the activities provided for removal and disposal of rubble from road.

- Reconstruction costs: related to the activities provided for removing the physical damage to capital assets including buildings, infrastructure and industrial plants through "in place" or "delocalized" reconstruction.

- Rehabilitation costs: related to the activities provided for removing the physical damage to capital assets, including buildings, infrastructure and industrial plants by the rehabilitation of damaged.

- Delocalization costs: related to the economic incentives provided for encouraging the consensual delocalization of part of population and of the economic functions not compatible with earthquake risk proneness. The percentage of resident population and of the number of economic factors which are delocalized is linked to the percentage of the volume of residential buildings and of industrial plants which will be subject to delocalized reconstruction interventions.

- Human health intervention costs: related to the health care management as the implementation of advanced medical structures, the strengthening of the existing local health structures, the identification of poor people (elderly and disabled), the psychological and social assistance.

- Back home costs: related to the activities provided for the "back home" of the population evacuated from the emergency area.

\section{Indirect damage costs}

The most important indirect, tangible cost categories are [19]:

- Decrease in local value added due to psychological effects: estimated through the comparison of the value of the production in two different 
moments in order to explore the psychological effects caused by emergency on resident population and, consequently, on human labour.

- Change in Gross Local Product or local valued-added: referred to the reduction of the flows of goods and services, which can be bought and sold in markets. It can include, for example, lower output from damaged or destroyed assets and infrastructure and loss of income due to damage to marketing infrastructure.

\section{Software tool}

In the CRISMA project, a software tool based on the economic evaluation approach presented in section 3 will be developed to make the assessment procedure usable in practice.

Fig. 3 presents the software components that will be developed as well as the interfaces within the CRISMA architecture. The software tool is to be implemented by two software components. Economic impact calculation view (in the upper part of the diagram) is a user interaction component and provides a graphical user interface (GUI) for the end users. The other component in the lower of the diagram is a federated calculation and simulation model providing a service to calculate the costs of the crisis under investigation.

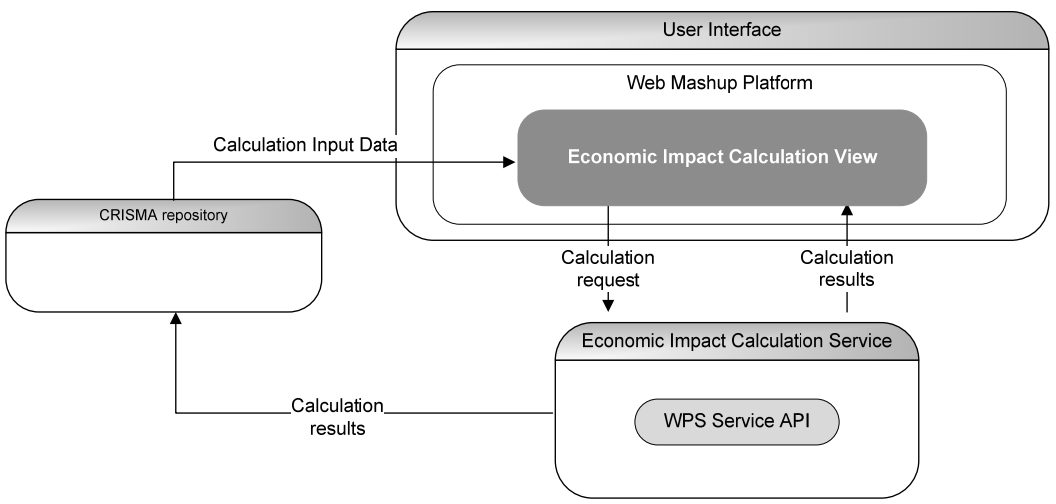

Figure 3: Software tool components.

As the diagram in Fig. 3 indicates, Economic impact calculation view receives some of the parameters from an external storage and some of the parameters are entered by the user. The parameters are sent to Economic impact calculation service in a calculation request which will launch the calculation and/or simulation process implemented in the Web Processing Service WPS instance. When the requested economic impact calculation is dispatched, the calculation and simulation service provides the results back to the user interface.

In accordance with the CRISMA architectural requirements for user interaction components, Economic impact calculation view is provided as HTML5 JavaScript widget. The jQuery JavaScript library and Kendo UI 
framework are used to build the user interface. In accordance with the CRISMA architectural requirements for federated simulation models Economic impact calculation service will be provided as OGC (Open Geospatial Consortium [20]) WPS (Web Processing Service [21]). In spite of the fact that OGC WPS standard defines how geospatial services can be executed it can be used to describe any process and execute it by using predefined input and output parameters. PyWPS is a Python implementation of OGC's WPS 1.0.0 standard. PyWPS was chosen because it has received positive reviews and seemed appropriate for the purpose. For its simplicity and rapid deployment, CGI (Common Gateway Interface) was chosen but WSGI (Web Service Gateway Interface) version would be to recommend for its better performance to handle multiple processes [22]. The objective is that the economic impact calculation service could be implemented as a single Python process.

\section{Conclusions}

This paper proposes a practical approach for the economic assessment of mitigation investments for crisis management, designed to support long-term planning and decision-making. The approach covers the influence of economic impacts of mitigation measures and uncertainty on decisions. The study is based on research carried out in the CRISMA project. In the next phases of CRISMA, the approach will be further evaluated and tested. It is expected that in most cases, a different set of cost and benefit categories and decision criteria will be used without any changes needed in the overall structure of the assessment procedure. Furthermore, a software tool based on the assessment approach will be developed to make the assessment procedure practical.

As with any empirical research, the limitations of the proposed approach must be taken into account when interpreting the results. It may not cover all the important aspects of linking vulnerabilities and damages with economic factors. Special considerations must be made regarding the expert judgement and expert panels. There are some generally recognised problems in expert judgement, such as subjectivity and overconfidence of the experts. Thus, the coverage of the expert group and competence of the experts is of prime importance.

However, the approach provides a practical structure to the integration of economic aspects of crises into the decision-making on mitigation measures. We believe that the developed approach fills its intended purpose as an easy-to-apply assessment approach. Furthermore, the approach enhances the transparency of investment decision-making and contributes to the more comprehensive use of available information affecting the cost effectiveness of different mitigation investments.

\section{References}

[1] Heikkilä, A. M., Molarius, R., Rosqvist, T. \& Perrels, A. Mitigating the impacts of extreme weather originated disasters by simulating the effects of different preparation and action decisions of crisis management. 
Programme and abstracts of the Second Nordic International Conference on Climate Change. Adaptation research meets adaptation decisionmaking. T. Carter, A. Perrels \& M. Hildén, p. 61, 2012.

[2] Räikkönen, M., Rosqvist, T., Poussa, L. \& Jähi, M. A Framework for Integrating Economic Evaluation and Risk Assessment to Support Policymakers' Security-related Decisions. PSAM11 \& Esrel 2012 Int'l conference proceedings. Scandic Marina Congress Centre, Helsinki, Finland, 25-29 June 2012. USB memory stick, p. 18.

[3] Meyer, V., Becker, N., Markantonis, N., Schwarze, R., van den Bergh, J. C. J. M., Bouwer, L. M., Bubeck, P., Ciavola, P., Genovese, E., Green, C., Hallegatte, S.,Kreibich, H., Lequeux, Q., Logar, I, Papyrakis, E., Pfurtscheller, C., Poussin, J., Przyluski, V., Thieken, A. H. \& Viavattene C. Review article: Assessing the costs of natural hazards-state of the art and knowledge gaps. Natural Hazards and Earth System Sciences. 13, 1351-1373, 2103.

[4] Götze U., Northcott D., Schuster P. Investment Appraisal: Methods and Models. Springer-Verlag: Berlin - Heidelberg, 2008.

[5] Pike R., Neale B. Corporate Finance and Investment: Decisions and Strategies, 4th ed. Prentice Hall: Harlow, 2003.

[6] Keeney, L. \& Raiffa, H. Decisions with Multiple Objectives: Preferences and Value Trade-offs. Cambridge University Press. 1993.

[7] Boardman A.E., Greenberg D.H., Vining A.R., Weimer, D.L. Cost-Benefit Analysis: Concepts and Practice, 3rd ed. Prentice Hall, 2006.

[8] Fuguitt, D. \& Wilcox, S.J. Cost-Benefit Analysis for Public Decision Makers. Quorum Books; Westport, CT, 1999.

[9] IEC 60300-3-3 ed2.0. Dependability management - Part 3: Application guide - Life cycle costing, 2004.

[10] Guha-Sapir, D. \& Santos, I. (Eds.). The Economic Impacts of Natural Disasters. OUP, USA. 368 pages. 2013.

[11] De Groeve, T., Poljansek, K. \& Ehrlich, D. Recording Disaster Losses. Recommendations for a European approach. JRC Scientific and policy Reports. 72 pages, 2013.

[12] McKenzie, E., Prasad, B \& Kaloumaira, A. Guidelines for Estimating the Economic Impact of Natural Disasters in the Pacific. The Australia Agency for International Development. pp. 1-38, 2005.

[13] Middelmann, M. H. (Ed.). Natural Hazards. Identifying Risk Analysis Requirements in Australia. Chapter 2: Impact of Natural Disasters. Department of Industry, Tourism \& Resources Minister for Industry, Tourism \& Resources: The Hon. Ian Macfarlane, MP Parliamentary Secretary: The Hon. Bob Baldwin, MP. pp. 7-29, 2007.

[14] Moe, T. L., Gehbauer, F., Senitz, S. \& Mueller, M. Balanced Scorecard for Natural Disasters on Development in the Pacific. Disaster Prevention and Management, Vol. 16 No. 5. pp. 785-806, 2007.

[15] Millet, I. \& Wedley, W.C. Modelling risk and uncertainty with the analytic hierarchy process. Journal of Multicriteria Decision Analysis; Mar/Apr 2002; 11; 2. pp. 97-107, 2002. 
[16] Tavana M. Euclid: Strategic Alternative Assessment Matrix. Journal of Multicriteria Decision Analysis. Mar/Apr 2002; 11; 2. pp. 75-96, 2002.

[17] Cavasogly H. Making Sound Security Investment Decisions. Journal of Information Privacy \& Security, 6(1), 53-71, 2010.

[18] Cellini, S. R. \& Kee J.E., "Cost-Effectiveness and Cost-Benefit Analysis," (Chapter 25) Handbook of Practical Program Evaluation, Third Edition, edited by Joseph S. Wholey, Harry P. Hatry, and Kathryn E. Newcomer. San Francisco: Jossey-Bass, 2010.

[19] Zuccaro G., .Leone M.F. Del Cogliano D., Sgroi A., Economic impact of explosive volcanic eruptions: A simulation-based assessment model applied to Campania region volcanoes, Journal of Volcanology and Geothermal Research, Volume 266, 1-15, 2013.

[20] Open Geospatial Consortium, www.opengeospatial.org

[21] Web Processing Service, www.opengeospatial.org/standards/wps

[22] Boerboom, J., Implementing the WPS Standard. A Case Study for Dissemination of Coastal and Marine Tools. Geographical Information Management and Applications. Delft University of Technology, the Netherlands, 2013. 